\title{
Störfall Jugend
}

Erhard Taverna

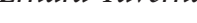

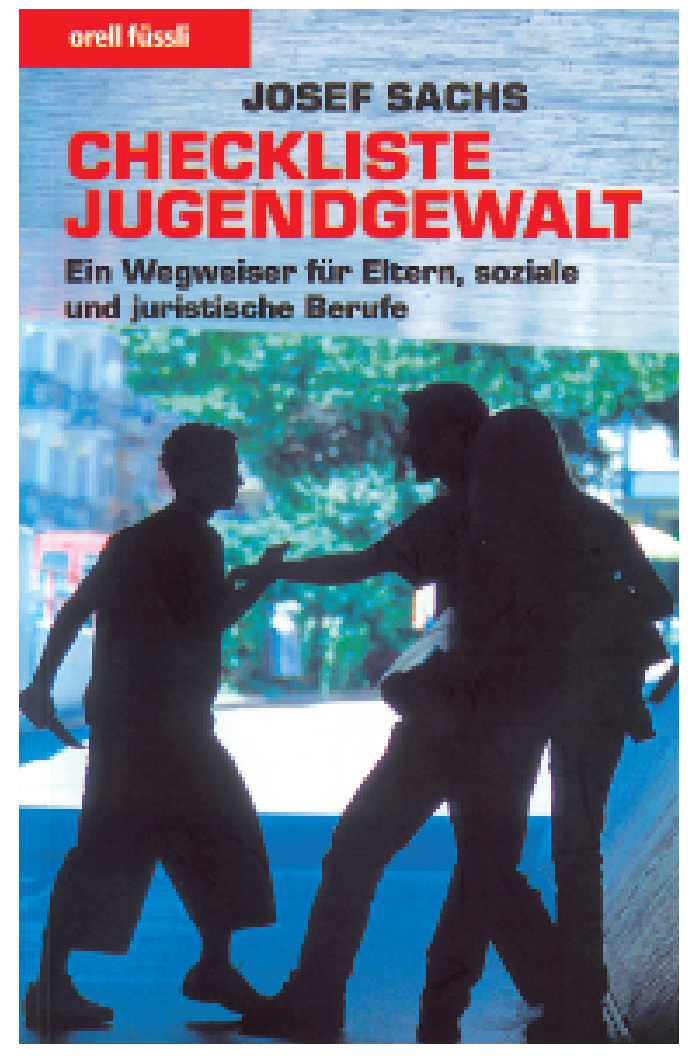

Laut einer SRG-Umfrage will die Mehrheit der Schweizer Bevölkerung mit härterer Repression und besserer Integration gegen die Jugendgewalt vorgehen. Das Jugendstrafrecht soll verschärft und jugendliche Straftäter ausländischer Herkunft sollen ausgebürgert werden. So war es auch nicht erstaunlich, dass an den 42. Solothurner Filmtagen 2007 unter 300 Filmen auch ein gutes Dutzend spezifische Jugendprobleme, wie Gewalt, Suizid, Drogen und Arbeitslosigkeit, thematisierte.

Am meisten zu reden gab der spannende und brutale Film «Breakout» von Mike Eschmann, der konsequent den Rap-Kodex von Ehre, Rache und Selbstjustiz in ein vorstädtisches HiphopDrama übersetzt. In ein Lehrstück für Eltern, doch leider nicht für die Oberstufe, muss man anfügen, denn die Jugendbehörde gab den Film erst ab 16 Jahren frei. Realistisch mag er sein. Aber aufklärend oder gesellschaftskritisch ist er nicht. Das besorgen kleinere, dokumentarische Filme weit besser. Zum Beispiel die zweijährige Begleitung von Tim und Gibran auf einer Odyssee durch geschlossene psychiatrische Ab- teilungen, Haftanstalten, Pflegefamilien und Gruppentherapien. Die Regisseure Bernhard Weber und Robi Müller zeigen sensibel und eindrücklich in ihrem Werk «Faustrecht» zwei Täter, die zugleich auch Opfer sind. Zwei dissoziale, charmante Übeltäter, gefühllos und narzisstisch, bindungslos, verletzlich und immer auf der Flucht vor sich selber. Eindrücklich auch eine Produktion von «Temps présent» der TSR von Hélène Faucherre und Jean-Philippe Schaller mit dem Titel «Les machos des préaux», die Machos der Schulhöfe. Beeinflusst von Gewaltrap und Pornographie verliert ein Teil der Schüler den Boden unter den Füssen, prügelt, vergewaltigt und erpresst. Allein im Kanton Waadt wird 2005 die Zahl der Opfer sexueller Gewalt auf rund 1200 geschätzt. Es gab weitere Filme, wie den in Nyon preisgekrönten Film «Geisendorf» von Frédéric Baillif, der das Leben herumlungernder Jugendlicher in einem berüchtigten Park der Stadt Genf demonstriert, oder den Dokufilm «Die Überflüssigen» von Andrea Bürgi, in dem zwei arbeitslose Jugendliche einen Platz in der Gesellschaft suchen.

Zahlreiche Ärztinnen und Ärzte sind in der Alltagspraxis, im schulärztlichen Dienst, in der Notfallstation oder im Kinderschutzzentrum mit Jugendproblemen konfrontiert. Für sie hat Josef Sachs, Facharzt für Psychiatrie und Psychotherapie, eine «Checkliste Jugendgewalt» verfasst. Der erfahrene Gerichtspsychiater bietet einen prägnanten und umfassenden Wegweiser für Eltern, soziale und juristische Berufe, der in aller Kürze eine berufliche und private Orientierungshilfe ermöglicht. Ihm gelingt das Kunststück, in zahlreichen, kurzen Kapiteln komplexe Phänomene der Gewalt wie Migration, Suchtmittel, Suizide, Strassenverkehr, Sport und Vandalismus übersichtlich und praxisorientiert darzustellen.

Es ist $\mathrm{zu}$ hoffen, dass die exemplarischen Dokumentationsfilme ihr Publikum auch wirklich erreichen. In ihnen sind die Fördergelder am besten angelegt. Sie liefern nicht Wahlkampfmunition, sondern Aufklärung, sie erzeugen keine Paranoia, dafür den Wunsch, die vielen Übel an den Wurzeln zu packen. Etwa ein 10minütiger Kurzfilm wie «Selma» von Bernie Forster, der einer witzig-frechen Oberstufenschülerin das Wort erteilt, die wegen ihres «falschen» Namens, trotz perfektem Schweizerdeutsch, keine Lehrstelle findet, oder der längere Dokufilm «Warten 
auf die Zukunft» von Leonidas Bieri über vier junge Albaner, die uns aus ihrer Heimat erzählen, wie das so ist, wenn man seit sechs Jahren absolut keine Chance hat, eine anständige Arbeit zu finden. Es sind diese stilleren Produktionen, die trotz ihres düsteren Inhaltes Hoffnung verbreiten. Hoffnung, weil sie die Bedürfnisse von jungen Menschen betonen: den Anspruch auf Liebe, Respekt und Arbeit, den Anspruch auf Vorbilder, Schulung und Aufnahme in die Gesellschaft, auf Einhaltung der Menschenrechte. An diesen Massstäben wird die geforderte Integration zu messen sein. Denn die Jugend als Störfall spiegelt eine Welt, die sie nicht ausgesucht hat. Eine CH-Welt, die gnadenlos vermarktet, was Profit bringt, die gerne Gesundheitskampagnen startet und an der Schule spart, eine, die lieber in Gegengewalt investiert als in die Sanierung eigener Defizite. Josef Sachs benennt am Ende seiner Checkliste einige wenige Aspekte langfristiger Prävention: das Verhindern von Segregation und Subkulturen, Konsens von Grundwerten und rasche Intervention bei Regelverstössen. Die Liste lässt sich auch für unser Land beliebig lange fortsetzen.

- Josef Sachs. Checkliste Jugendgewalt. Zürich: Orell Füssli Verlag AG; 2006. 160 Seiten.

- Breakout. Regie: Mike Eschmann. Distribution Buena Vista, Zürich. 2007.

- Faustrecht. Regie: Bernhard Weber und Robi Müller. Distribution Docufactory, Zürich. 2006.

- Les machos des préaux. Regie: Hélène Faucherre, Jean-Philippe Schaller. Temps Présent, Télévision Suisse Romande. 2006.

- Geisendorf. Regie: Frédéric Baillif. Distribution Point Prod SA, Genève. 2006.

- Die Überflüssigen. Regie: Andrea Bürgi. Distribution Hochschule für Gestaltung und Kunst Zürich. 2006.

- Selma. Regie: Bernie Forster. World Sales base-court, Lausanne. 2007

- Warten auf die Zukunft. Regie: Leonidas Bieri. Distribution Burgauer, Zürich. 2007. 